\title{
GLL
}

$0=\square$ Geomatics, Landmanagement and Landscape No. $4 \cdot 2020,77-89$

\section{ANALYSIS OF THE DENSITY OF THE NATIONAL NETWORK OF REFERENCE STATIONS ON THE EXAMPLE OF ASG-EUPOS}

\author{
Dawid Kudas
}

\section{Summary}

Networks of reference stations play the role of sensors networks that continuously receive satellite signals. In this way, they provide data for many issues related to relative positioning. The density of reference stations network has an impact on measurements with kinematic techniques (e.g. RTK, NRTK) and the postprocessing of satellite observations recorded using the static technique. Networks of reference stations are divided according to their spatial range and the tasks they perform. The reference network can also be characterized by the network density. This article presents considerations concerning the determination of the average distance between the stations of national reference network, as well as between the stations of the higher accuracy network and the considered national network. The considerations relate to the example of the Polish ASG-EUPOS network. The average distance between the ASG-EUPOS network stations was determined in two-dimensional (2D) and three-dimensional (3D) space. It was determined that the average 3D distance between neighbouring ASG-EUPOS stations is approx. $42 \mathrm{~km}$. However, in the case of determining the average distance between the network points using the sides of Delaunay triangles, this value is approx. $70 \mathrm{~km}$. In the case of averaging the distance to six closest neighbours of each station, the obtained value was approx. $69 \mathrm{~km}$. The areas of the ASG-EUPOS network characterized by an inconvenient location in relation to the EUREF Permanent GNSS Network class A stations, which is a network of a higher accuracy class, to which the ASG-EUPOS is related, were also indicated.

\section{Keywords}

EPN • ASG-EUPOS's NNI • tie vector length • basis vector

\section{Introduction}

The development of measurement techniques and methods using Global Navigation Satellite Systems (GNSS) was accompanied by the development of networks of reference stations. These networks consist of a technical infrastructure capable of continuous recording of GNSS observations with antennas installed at designated points of the network, as well as of archiving, distributing and developing using the network's 
computing centre. Depending on the area in which the stations of a given network are located, following types of networks are distinguished: global, regional and national/ local. The reference station network that spans the globe is the International GNSS Service network (IGS network). It consists of heterogeneous stations belonging to many different organizations that combine their resources under the oversight of IGS for the common good [www.kb.igs.org]. The EUREF Permanent GNSS Network (EPN) that covers Europe serves as an example of a regional network. A network covering several countries can also be regarded as a regional network, such as European Position Determination System (EUPOS) running in European countries [www.eupos.org/ node/9] and the Continuously Operating Reference Stations (CORS) network operated by NOAA's National Geodetic Survey (NGS) covering the US and several neighbouring countries [www. ngs.noaa.gov/CORS/]. The CORS requires that new stations should be located more than $70 \mathrm{~km}$ from existing stations [CORS Guidelines 2018]. Examples of national networks are the ASG-EUPOS in Poland, the SK-POS in Slovakia, the CZEPOS in the Czech Republic, the LIT-POS in Lithuania, or the SAPOS in Germany. In addition to national networks managed by state institutions, commercial networks developed and managed by leading geodetic companies have also developed successfully. National and commercial reference networks should maintain a density between 50 and $70 \mathrm{~km}$ [e.g. Wang et al. 2010]. For example, there are three commercial networks operating in Poland nationwide: TPI NETpro, VRSNet and HxGN SmartNet and two local networks covering the southern part of Poland: NadowskiNET and RtkNet.

Observations recorded by networks of reference stations support the determination of three-dimensional positions on the surface of the Earth and its vicinity, and provide data for research in the field of meteorology and geophysics. Reference station networks also serve the physical implementation of reference systems, for example the IGS network is responsible for the realisation of the International Terrestrial Reference System (ITRS) in the form of the International Terrestrial Reference Frame (ITRF). On the other hand, the EPN network enables the implementation of the European Terrestrial Reference System (ETRS89) in the form of the European Terrestrial Reference Frame (ETRF) applicable in Europe. The CORS network is responsible for the implementation of the National Spatial Reference System (NSRS) applicable in the USA. Global networks enable the implementation of global coordinate systems, therefore they are superior in relation to national reference networks executing the state coordinate systems. National and commercial reference station networks with an appropriate density are used for measurements using relative techniques, e.g. the Real Time Kinematic (RTK) and Network Real Time Kinematic (NRTK). Archival GNSS observations recorded by reference stations also enable position determination in the post-processing mode of static GNSS user observations. Time series of precise coordinates of GNSS reference stations, together with observations from other geodetic measurement techniques, make it possible to study the movement of tectonic plates [e.g. Prawirodirdjo and Bock 2004, Uzel et al. 2013], ground deformation [e.g. Alizadeh-Khameneh et al. 2018, Turen and Sanli 2019, Du et al. 2020], monitoring of engineering structures [e.g. Yavaşoğlu et al. 2018], or modelling changes taking place in 
the layers of the atmosphere, especially in the troposphere and ionosphere [e.g. Kablak et al. 2016].

The aim of the research undertaken in this article is to determine the density of a reference station network with a national range by assessing the average distance between stations. The sides of the Delaunay triangles and the distances to the nearest neighbouring network station were used for determining the distance between network points. The spatial analysis determining the mutual positions of the network points was carried out in the Cartesian two-dimensional and three-dimensional space, while discerning between domestic and foreign stations of the studied network. The method of determining the relationship between the national grid and the grid of a higher accuracy class was also presented. Spatial analyses were carried out on the example of the Polish national ASG-EUPOS network and a part of the EPN network covering the territory of Poland and its border areas.

\section{Material and methods}

\section{Methods}

In order to characterize the geometrical relations between the points forming the network (reference stations), the rules for determining the length of the sections connecting the network points should be defined. The sections determining the distance between the points of a reference network according to the Euclidean metric can be calculated both in a selected two-dimensional Cartesian coordinate system (in the projection to the plane) and in a three-dimensional coordinate system. In the reference network composed of $N$ stations, it is possible to assess distances of each station to the rest of $N-1$ stations of the network (neighbours) and calculate the number $K$ specifying the number of unique sections between all points in the reference network according to the formula (1):

$$
K=N(N-1) / 2
$$

given:

$N$ - number of reference stations of the reference network.

The Nearest Neighbor Method (NN) can also be used in regard to reference station networks [e.g. Clark and Evans 1954, Mitchell 2005], which indicates the degree of concentration of the network points and the randomness of the distribution of points. This method allows to specify the Nearest Neighbor Index (NNI) that compares the distances between the nearest points and the distances that would come up in andom distribution of points. The NNI $<1$ indicates that the distances between the nearest points are smaller than in a random distribution, forming clusters. The NNI $>1$, on the other hand, shows that points are more regularly positioned than in a random distribution, thereby demonstrating an even distribution. Averaging the distances to the next few neighbours allows to determine the average distance of a station to the nearest network station, and thus examine the local network dependencies. If distances gener- 
ated from the next few neighbours for each network station are averaged, the mean network density for the selected neighbourhood level can be assessed.

Reference network points define an area that can be divided using one of the basic notions of computational geometry, that is, triangulation. Therefore, a network of reference stations can be presented as a set of triangles with vertices at network points in a $2 \mathrm{D}$ and a $3 \mathrm{D}$ space. For this purpose, a common triangulation method called Delaunay triangulation can be applied [see e.g. Lee and Schachter 1980, Gallier 2011], and the distances between the reference network points equated with the side lengths of the designated triangles. This approach provides a connection between network points by the sides of adjacent triangles, continuously filling the area of network coverage. It thus examines local dependencies in a network operating on a large area, as it does not connect points at considerable distances. Average side length of triangles can serve as a description of the density of a reference station network. The analysis does not need to include these side lengths of triangles that exceed the adopted length in order to eliminate triangles emerging in the border areas of networks. For the reference networks created according to the EUPOS [2013] standard, it should be $100 \mathrm{~km}$, as this is supposed to be the maximum distance between the closest stations.

When analysing the locations of stations in a national reference networks in relation to a higher class network, the average distance to the closest neighbour belonging to the higher class network can be determined. For the analysis of 2D space, Voronoi polygons (also known as Thiessen diagrams) can be determined in reference to stations of higher class networks [see e.g. Pokojski and Pokojska 2018, Gallier 2011], presenting the spatial distribution of a national network in relation to points of higher class network. Voronoi polygons are used in the analysis of locations of reference stations [e.g. Muzondo et al. 2015, Calka et al. 2017, Kudas et al. 2020].

\section{The object of research}

The ASG-EUPOS network currently consists of 103 reference stations located on Poland's territory and 24 stations in its border areas with the neighbouring countries (Germany, the Czech Republic, Slovakia and Lithuania). Two of the ASG-EUPOS national reference stations function as stations for monitoring measurements with kinematic techniques (ID: DZWE and HOLO). The ASG-EUPOS network was established and developed in accordance with the EUPOS Guidelines [2006, 2008] and EUPOS Technical Standards [2008, 2013]. The ASG-EUPOS network was launched in 2008, and includes 19 EPN reference stations and 6 IGS Network stations (Fig. 1). Existing studies indicate that lengths from 10 to $65 \mathrm{~km}$ are typical in the ASG-EUPOS network [Calka et al. 2017]. In its first years of operation, the ASG-EUPOS used the Trimble VRS3Net software. The national reference stations are mostly located on the provincial and county public administration buildings, as well as research facilities and education buildings. In 2018, partial modernisation of the ASG-EUPOS network was completed, adapting 58 reference stations for recording satellite signals of GPS, Glonass, Galileo and BDS systems and providing software in computing 
cents for rendering access to the RTK and NRTK correction data based on these satellite systems. Leica GR30 receivers are installed on these stations. Trimble Pivot Platform software used since August 2013 has also been updated. The ASG-EUPOS network development plan envisages an expansion of the network by 19 new reference stations located in Poland. More information on The ASG-EUPOS network can be found on its website [www.asgeupos.pl]. Polish state spatial reference system is implemented by the ASG-EUPOS.

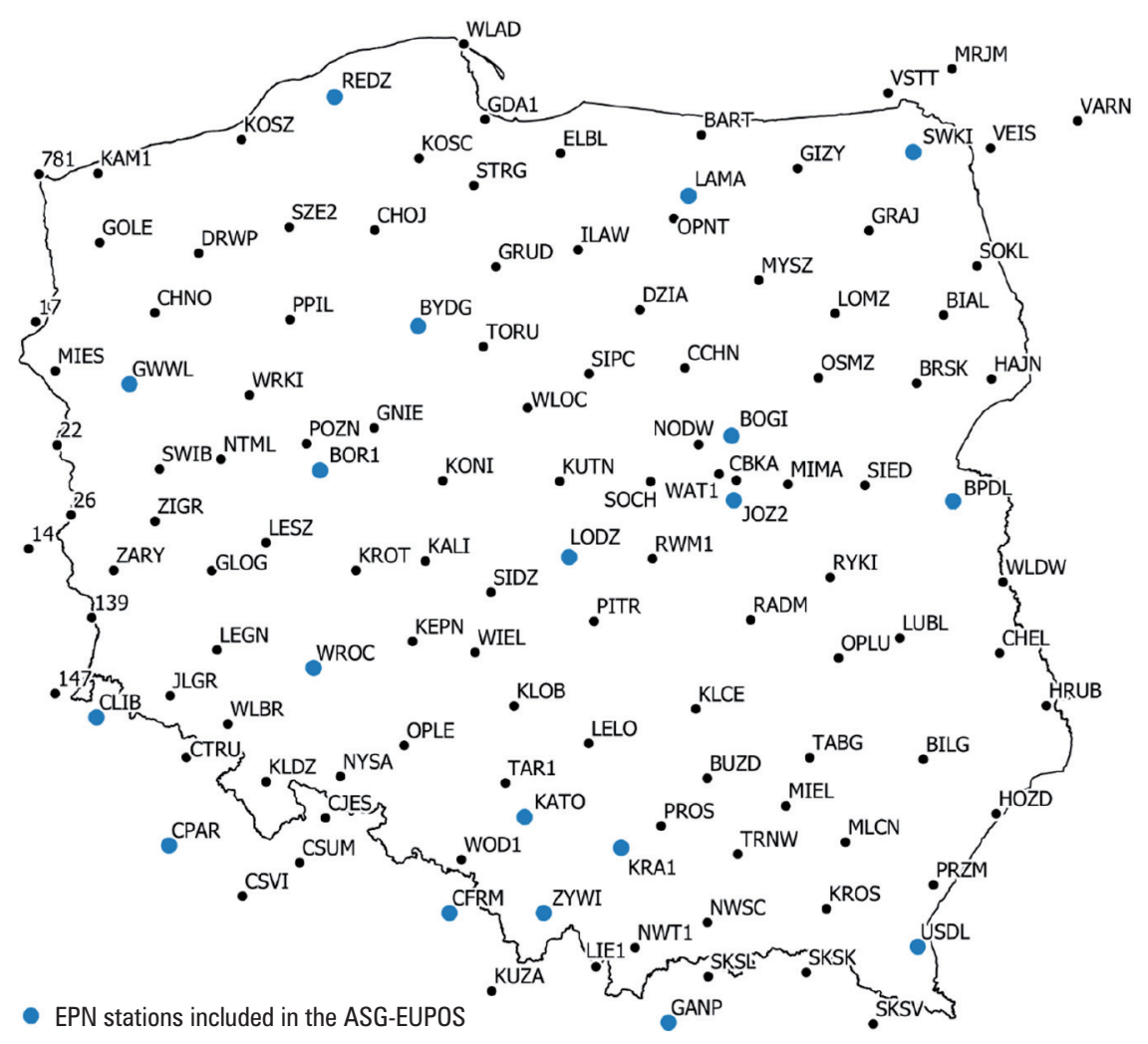

Fig. 1. Location of the ASG-EUPOS network stations

The study used the coordinates of 125 ASG-EUPOS stations (excluding 2 monitoring stations) in the PL-1992 (EPSG:2180) system and the PL-ETRF2000 system 2011.00 epoch, which is an implementation of the PL-ETRF89 system. These mappings employed the GRS80 ellipsoid. The accuracy of mapping the threedimensional position of the ASG-EUPOS station to a plane using the EPSG:2180 system is from -0.70 to $0.93 \mathrm{~m}$. Vector length calculations were performed to within $1 \mathrm{~m}$. In order to characterise the analysis variants more accurately, the results of the calculations were given with a recording accuracy of up to $0.1 \mathrm{~km}$, although the 
geometrical parameters of the reference networks were assumed to be delivered in full kilometres. ASG-EUPOS network points have a normal height $(H)$ from 7 to $704 \mathrm{~m}$ in the PL-KRON86-NH altitude system, which corresponds to the range of ellipsoidal heights $(h)$ calculated relative to the area of the ellipsoid GRS80 from 35 to $746 \mathrm{~m}$. The average normal height of the network points is $193 \mathrm{~m}$ and the average ellipsoidal height is $228 \mathrm{~m}$. The coordinates of 25 A class EPN reference stations located in Poland and near its borders were also used.

\section{Results}

The ASG-EUPOS network includes 18 class A EPN stations and 1 class B station. There are 7 class A EPN stations in the border areas of Poland notincluded in the ASG-EUPOS network (ID: WARN, POTS, CRAK, TUBO, BISK, BBYS, VLNS) The location of the 107 ASG-EUPOS stations, not class A EPN stations, can be examined in relation to 25 EPN stations, as belonging to a higher accuracy network (Fig. 2).

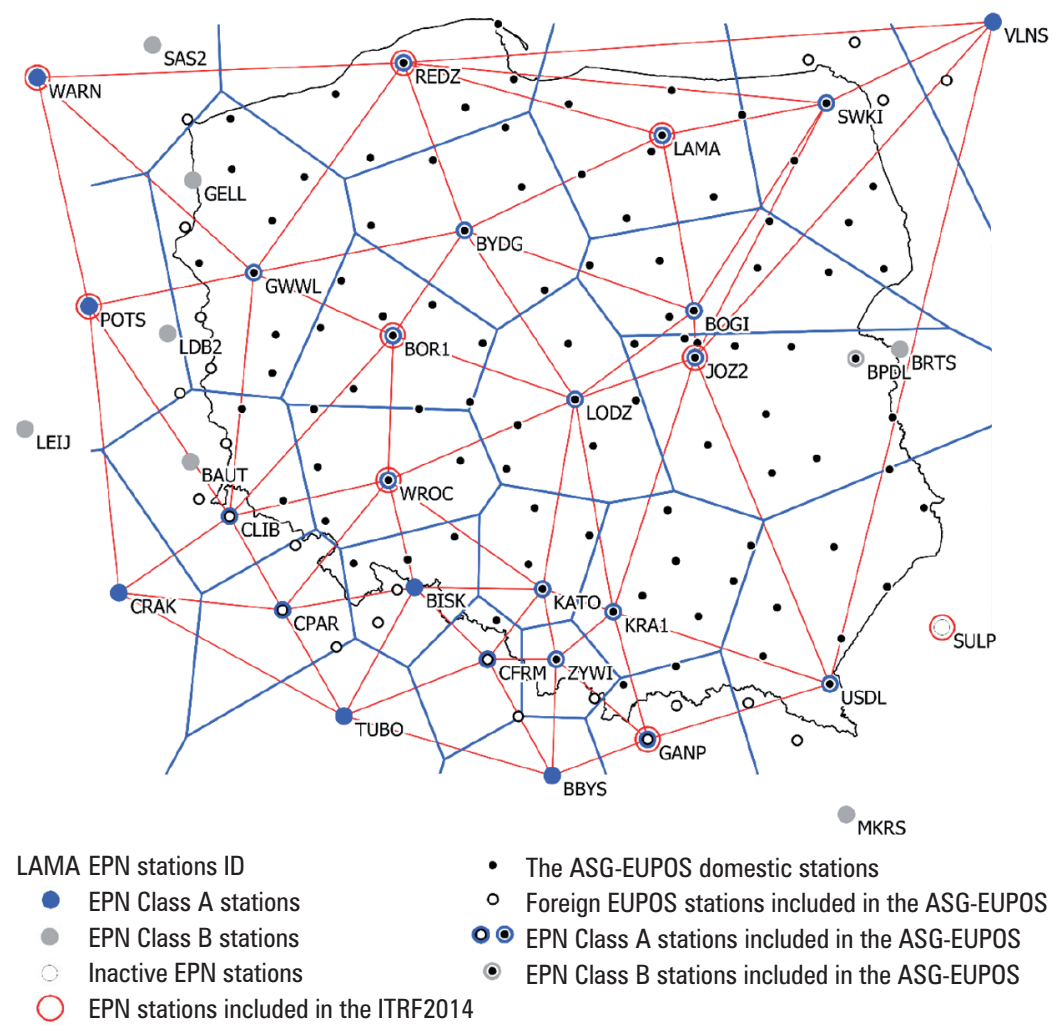

Fig. 2. Division of the ASG-EUPOS network using Delaunay triangulation and Voronoi polygons based on class A EPN stations 
JOZ2 is the closest station for about 10\% of the analysed ASG-EUPOS stations, not class A EPN stations, while GWWL is the closest station to 9\% of the ASG-EUPOS stations. The stations BOR1, LAMA, SWIKI, BOGI, BYDG and KRA1 are closest to about $6 \%$ of the ASG-EUPOS stations each. For each of the calculated Voronoi polygons, a CS shape factor [Osserman 1978] was specified, which ranged from 0.45 to 0.86 , obtaining an average value of approx. 0.75. The CS factor is lower than the squared polygon $(C S=0.78)$ for approx. $60 \%$ of the designated polygons. As a result, Voronoi polygons based on the location of class A EPN stations have an elongated shape and larger sizes, it is especially noticeable in the eastern part of the ASG-EUPOS network. This situation is due to, among others, inactive SULP stations and the absence of class A EPN stations along the Polish eastern border on the territory of Ukraine and Belarus. Such distribution of EPN stations leads to an elongation of the reference vector of the ASG-EUPOS stations located in the eastern part of Poland towards the class A EPN stations. Mean length of a 3D vector between ASG-EUPOS and non-class A EPN stations and the nearest class A EPN station is approx. $75 \mathrm{~km}$. Mean length of a 3D vector to the second nearest EPN station is about $115 \mathrm{~km}$. Mean length of a 3D vector between the ASG-EUPOS stations and the 3rd nearest EPN station is about $146 \mathrm{~km}$. When each ASG-EUPOS station is referenced to 3 nearest EPN stations, the mean length of the 3D vector is approx. $112 \mathrm{~km}$, and to 4 nearest EPN stations to is approx. $128 \mathrm{~km}$. When references to 5 and 6 nearest EPN stations are designated, the mean reference length is approx. $142 \mathrm{~km}$ and approx. $156 \mathrm{~km}$, respectively.

In the ASG-EUPOS network, vectors between a random station and other network stations, as well as vectors between national stations and all stations, or vectors exclusively between national stations, can be determined in a $3 \mathrm{D}$ and a $2 \mathrm{D}$ space. In the ASG-EUPOS network consisting of 125 reference stations, it is possible to designate 7750 non-recurring connections between all stations. When studying the spatial connection of each station locally, its reference to 9 nearest stations was identified, and for the general characteristics of the references, the mean values of the length of the reference vectors $(\mu)$, the standard deviations of the lengths of the reference vectors $(\sigma)$ and the coefficients of variation in the length of the reference vectors $\left(c_{v}\right)$ (Table 1$)$ were calculated. Values of mean vectors up to 9 closest neighbours in a $3 \mathrm{D}$ and a $2 \mathrm{D}$ space vary by up to approx. $40 \mathrm{~m}$. With the determination of the mean length of the reference vector to the 8th and subsequent neighbours, the standard deviation of vector length begins to exceed $20 \mathrm{~km}$, which significantly reduces the usefulness of these vectors to determine the density of the ASG-EUPOS network. For mean vectors up to 6 closest neighbours, the standard deviation of their length is between 10 and $18 \mathrm{~km}$. As to $3 \mathrm{D}$ vectors, a random ASG-EUPOS station is connected to the nearest station by a vector of mean length of $42.1 \mathrm{~km}$, while the ASG-EUPOS random national station is connected to the nearest station of the network by a vector length of $42.4 \mathrm{~km}$. In the case of vectors designated between national ASG-EUPOS stations, the mean vector is $43.8 \mathrm{~km}$. The NN algorithm indicated that the expected average distance value in the ASG-EUPOS network of 125 stations is approx. $29.7 \mathrm{~km}$ and the NNI is 1.42, i.e. there is an even distribution of the stations positions. 
Table 1. Mean 3D vector length to 9 nearest stations

\begin{tabular}{|c|c|c|c|c|c|c|c|c|c|}
\hline \multirow{2}{*}{$\begin{array}{c}\text { No. of } \\
\text { nearest } \\
\text { stations }\end{array}$} & \multicolumn{3}{|c|}{$\begin{array}{c}\text { all stations } \\
\text { to all stations }\end{array}$} & \multicolumn{3}{c|}{$\begin{array}{c}\text { national stations } \\
\text { to all stations }\end{array}$} & \multicolumn{3}{c|}{$\begin{array}{c}\text { national stations } \\
\text { to national stations }\end{array}$} \\
\cline { 2 - 11 } & $\mu[\mathrm{km}]$ & $\sigma[\mathrm{km}]$ & $c_{v}$ & $\mu[\mathrm{km}]$ & $\sigma[\mathrm{km}]$ & $c_{v}$ & $\mu[\mathrm{km}]$ & $\sigma[\mathrm{km}]$ & $c_{v}$ \\
\hline 1 & 42.1 & 11.4 & 0.27 & 42.4 & 11.8 & 0.28 & 43.8 & 11.8 & 0.27 \\
\hline 2 & 52.8 & 11.4 & 0.22 & 52.4 & 11.6 & 0.22 & 54.2 & 12.5 & 0.23 \\
\hline 3 & 61.1 & 12.7 & 0.21 & 59.8 & 11.9 & 0.20 & 62.6 & 13.0 & 0.21 \\
\hline 4 & 69.6 & 14.1 & 0.20 & 67.7 & 13.0 & 0.19 & 71.3 & 14.9 & 0.21 \\
\hline 5 & 78.0 & 14.7 & 0.19 & 75.6 & 13.0 & 0.17 & 79.6 & 15.9 & 0.20 \\
\hline 6 & 86.2 & 17.5 & 0.20 & 83.1 & 15.3 & 0.18 & 87.5 & 17.7 & 0.20 \\
\hline 7 & 92.7 & 17.5 & 0.19 & 89.5 & 15.5 & 0.17 & 94.8 & 18.4 & 0.19 \\
\hline 8 & 99.8 & 19.3 & 0.19 & 96.0 & 16.2 & 0.17 & 101.9 & 19.7 & 0.19 \\
\hline 9 & 107.1 & 20.6 & 0.19 & 103.2 & 17.1 & 0.17 & 109.8 & 20.3 & 0.19 \\
\hline
\end{tabular}

For 95.5\% of ASG-EUPOS stations, the length of 3D vectors to 4 nearest stations is not exceeded $100 \mathrm{~km}$, as evidenced by the mean vector length and the double standard deviation from the population. By contrast, for $68 \%$ of stations, the values of $3 \mathrm{D}$ vectors to the 5 th nearest station do not exceed $100 \mathrm{~km}$. Population standard deviation values and mean $3 \mathrm{D}$ vector length values indicate that vectors up to the 7 th and next stations exceed $100 \mathrm{~km}$ in the ASG-EUPOS network. The coefficient of variation for vectors to the nearest station reaches a value of approx. 0.27 , while for vectors to subsequent stations approx. 0.20. The inclusion of foreign stations in the ASG-EUPOS network and the subsequent neighbours of national stations has particularly improved the statistics of the mean vector to 3 (Table 1 ). The length of the $3 \mathrm{D}$ vector to the 4 th and subsequent nearest stations exceeds $100 \mathrm{~km}$ for stations 0781, HOZD and VARN. This value is also exceeded for the 5 th and subsequent nearest stations for BART, HAJN, HRUB, KOSZ, MRJM, SKSV stations. Most of these stations are external to the ASG-EUPOS network. The analysis concludes that the spatial distribution of the stations is beneficial for the use of an algorithm of automatic postprocessing of static satellite observations (APP) calculating vectors of up to 6 nearest reference stations in the POZGEO sub-service of the ASG-EUPOS system. The coordinates of the point measured using the static technique in majority of the territory of Poland will be determined by reference vectors not exceeding $100 \mathrm{~km}$, the components of which will be gauged with high accuracy. Measurement experiments also indicate that a failure of one of the neighbour stations [e.g. Kudas and Wnęk 2019], or limiting the number of reference vectors to 5 does not reduce the accuracy of the coordinates determined using the POZGEO APP [Kudas and Wnęk 2020]. 


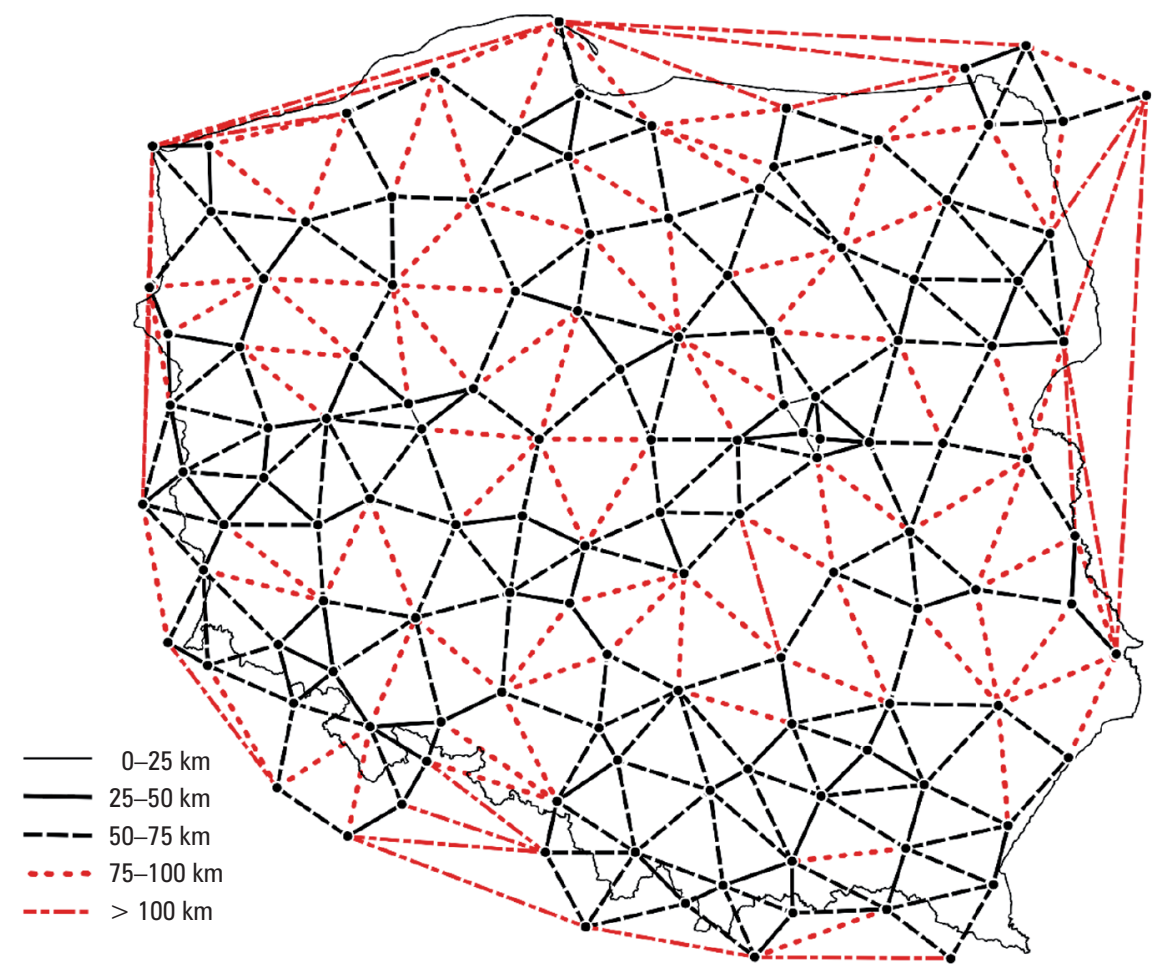

Fig. 3. Classification of side lengths of Delaunay triangles based on the ASG-EUPOS network points

The division of a 3D space limited by the location of a ASG-EUPOS station using the Delaunay triangulation available in QGIS 3.12 has generated 357 connections between stations (Fig. 3). Length classification of these connections has shown that, in the case of the ASG-EUPOS network, the distances between stations in the range of $50-75 \mathrm{~km}$ compose about $45 \%$ and distances in the range of $25-50 \mathrm{~km}$ - about $23 \%$. On the other hand, distances exceeding $100 \mathrm{~km}$ account for about $6 \%$ of the designated connections. The mean length of the calculated vectors is approx. $69.5 \mathrm{~km}$ with a coefficient of variation of 0.54 , while after excluding sections $>100 \mathrm{~km}$ the mean is approx. $62.3 \mathrm{~km}$ and $\mathrm{cv}$ amounts to 0.28 . The average difference between the lengths of connections specified in a $3 \mathrm{D}$ and a $2 \mathrm{D}$ space is approx. $21 \mathrm{~m}$. By analysing the spatial location of the connections thus formed, it is possible to see the concentration of short connections in the belt within the network extending towards the NE-SW and in its southern part. In the central part of the ASG-EUPOS network the concentrations of stations (ID: NODW, BOGI, WAT1, CBKA, JOZ2) are apparent in the vicinity of the Warsaw agglomeration, which are characterized by the smallest distance values to the nearest stations regardless of the number of nearest stations analysed. 
If the distance between stations in the ASG-EUPOS network is defined as a connection to 3 closest neighbours of each station, the mean 3D vector would be approx. 54.4 $\mathrm{km}$. Whereas, for the connection of each station with 4 closest neighbours, this value is approx. $59.2 \mathrm{~km}$ and similarly connections to 5 nearest neighbours - approx. $64.0 \mathrm{~km}$, and to 6 closest neighbours - approx. $68.7 \mathrm{~km}$. At the same time, the standard deviation would not exceed $20 \mathrm{~km}$. The characteristics of the ASG-EUPOS station connections through the vectors to 5 and 6 closest neighbours are shown in Figure 4.

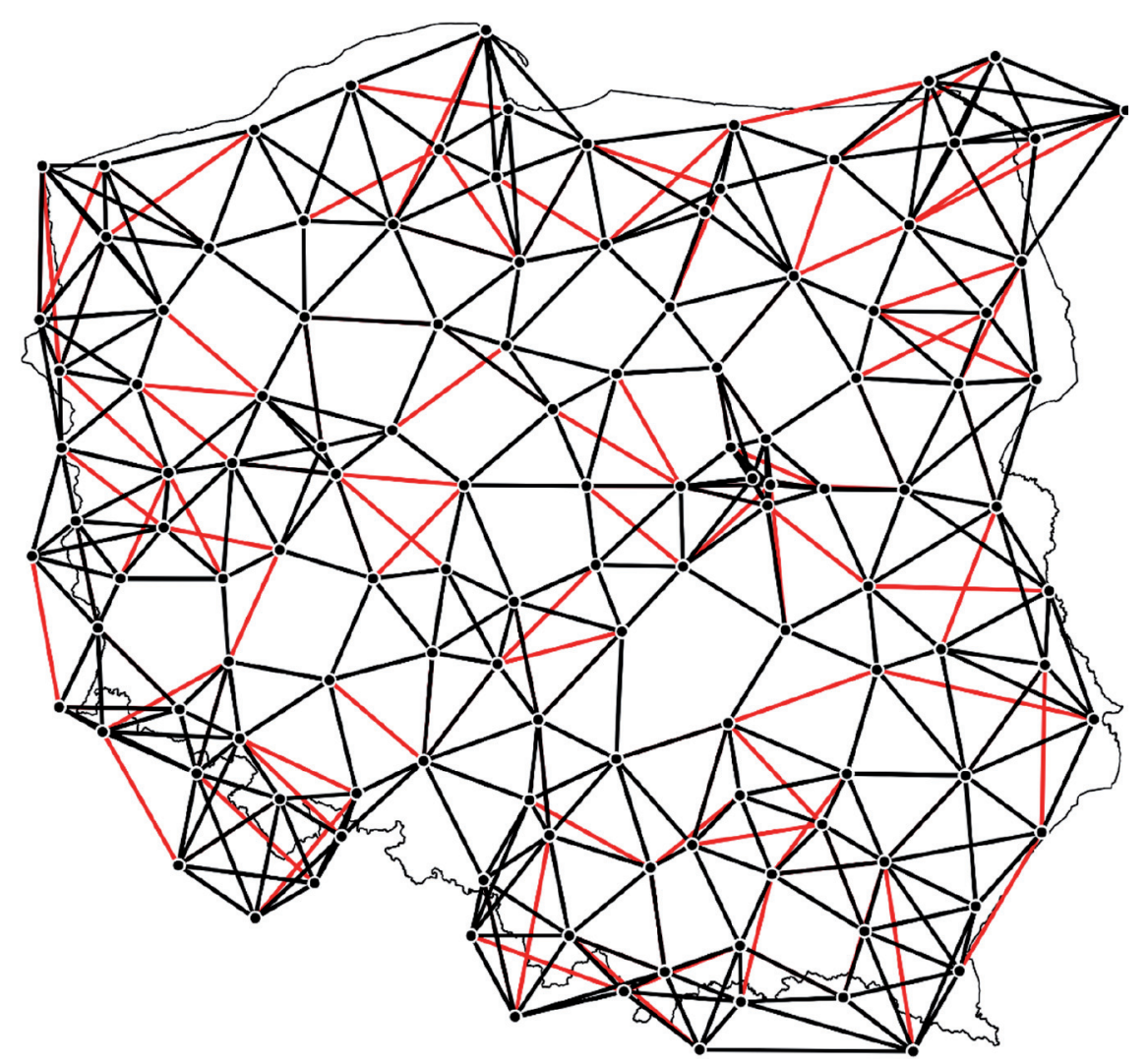

Fig. 4. Location of the $2 \mathrm{D}$ distances to 5 closest neighbours (black) and the distances to the 6th nearest neighbour (red)

When the mean distance between stations is determined by averaging the distance between each station and its 6 closest neighbours, the mean length close to $70 \mathrm{~km}$ using Delaunay triangulation was obtained, while achieving a lower coefficient of variation in the length of $3 \mathrm{D}$ vectors $\left(c_{v}=0.31\right)$. Whereas, the average distance value using Delaunay triangulation after excluding sides longer than $100 \mathrm{~km}$ is approx. $62 \mathrm{~km}$ and is similar to the figures for linking the ASG-EUPOS points involving vectors to 5 clos- 
est neighbours. Both solutions are characterised by a similar coefficient of variation in vector length. However, a spatial analysis of the location of mean lengths showed that the use of the sides of Delaunay triangles, which continuously cover the area of the network, is an optimal method for determining the average distance between the points of the reference station network. Using average distances of up to 5 or 6 nearest neighbours to determine the density of the analysed network gives clusters of connections (Fig. 4), therefore it represents the local density of the network better than the global density. By analysing Figure 3, and Figure 4 in particular, it can be estimated that the density of the ASG-EUPOS network by about 10 stations will significantly improve the currently observed average distance between stations. Depending on the adopted approach, the density of the ASG-EUPOS reference network ranges from 62 to $70 \mathrm{~km}$, which guarantees accurate situational measurements using NRTK due to the geometry of the reference network [e.g. Wang et al. 2010]. The specified network densities also show that in most areas of Poland for RTK measurements the length of the base vector to the ASG-EUPOS network stations will not exceed $35 \mathrm{~km}$. It should also be borne in mind that the quality of the surveying network is also influenced by the topography of the site [see e.g. Bielecka et al. 2014, Calka et al. 2017] and the accuracy of measurements using RTK and NRTK techniques does not depend solely on the geometrical parameters of the network.

\section{Conclusions}

The analyses carried out show that, in the case of a reference station network adapted to an area similar to the territory of Poland, which corresponds to a maximum difference in the height of the network points of approx. $700 \mathrm{~m}$, the spatial analysis of the network of reference stations may be reduced to a $2 \mathrm{D}$ analysis. The current spatial configuration of the class A EPN stations relative to the ASG-EUPOS stations is characterized by a mean vector length between the ASG-EUPOS stations and the EPN stations at of approx. $75 \mathrm{~km}$. The absence of a class A EPN stations in the eastern part of the ASG-EUPOS network should be considered an adverse effect in terms of transferring the ETRF system onto Poland. The future acquisition of a class A station status by existing class B EPN stations (ID: BPDL or BRTS) will have a positive impact on the spatial location of the ASG-EUPOS stations relative to the EPN stations. The mean length of a 3D vector between the nearest points of the ASG-EUPOS network is approx. $42 \mathrm{~km}$, both for the connection between all stations and only between national stations. The ASG-EUPOS network densities obtained using the sides of Delaunay triangles and distances up to 5 and 6 nearest neighbours do not exceed 70 $\mathrm{km}$ and indicate that the ASG-EUPOS network meets the geometrical requirements specified for reference networks guaranteeing accurate situational measurements using NRTK technology. On the other hand, the possible density of the ASG-EUPOS network should have a positive impact on the accuracy of the determination of the altitude coordinate. 


\section{References}

Alizadeh-Khameneh M., Eshagh M., Jensen A. O. 2018. Optimization of deformation monitoring networks using finite element strain analysis. Journal of Applied Geodesy, 12(2), 187197. DOI:10.1515/jag-2017-0040

Bielecka E., Pokonieczny K., Kamiński P. 2014. Study on spatial distribution of horizontal geodetic control points in rural areas. Acta Geodaetica et Geophysica, 49, 357-368. DOI:10.1007/s40328-014-0056-6

Calka B., Bielecka E., Figurski M. 2017. Spatial pattern of ASG-EUPOS sites. Open Geosciences, 9(1), 613-621. DOI:10.1515/geo-2017-0046

Clark P.J., Evans F.C. 1954. Distance to nearest neighbour as a measure of spatial relationships in populations. Ecology, 35, 445-453.

CORS Guidelines: Guidelines for New and Existing Continuously Operating Reference Stations (CORS) National Geodetic Survey National Ocean Survey, NOAA, Silver Spring, MD 20910, August 2018. www.ngs.noaa.gov

Du Y., Huang G., Zhang Q., Gao Y., Gao Y. 2020. Asynchronous RTK Method for Detecting the Stability of the Reference Station in GNSS Deformation Monitoring. Sensors 20, 1320. DOI:10.3390/s20051320

EUPOS Guidelines For Cross-Border Data Exchange, 2006. www.eupos.org/node/8.

EUPOS Guideline for EUPOS Reference Frame Fixing, 2007. www.eupos.org/node/8.

EUPOS Technical Standards. Revised 3rd Edition, Resolution of the International EUPOS ${ }^{\circledR}$ Steering Committee 23rd Conference, Tbilisi, Georgia, 7-8 May 2013. www.eupos.org/node/8.

EUPOS Technical Standards, rev. 2, 2008. www.eupos.org/techsd.

Gallier J. 2011. Dirichlet-Voronoi Diagrams and Delaunay Triangulations. In: Geometric Methods and Applications. Texts in Applied Mathematics, 38. Springer, New York, NY. DOI:10.1007/978-1-4419-9961-0_10

Kablak N., Reity O., Ştefan O., Rădulescu A.T.G.M., Rădulescu C. 2016. The Remote Monitoring of Earth's Atmosphere Based on Operative Processing GNSS Data in the UA-EUPOS/ ZAKPOS Network of Active Reference Stations. Sustainability, 8(4), 391. DOI:10.3390/ su8040391

Kudas D., Wnęk A. 2019. Operation of ASG-EUPOS POZGEO sub-service in the event of failure of reference stations used in the standard solution - case study. Geomatics, Landmanagement and Landscape, 4, 59-71. DOI:10.15576/GLL/2019.4.59

Kudas D., Wnęk A. 2020. Validation of the number of tie vectors in post-processing using the method of frequency in a centric cube. Open Geosciences, 12, 1, 242-255. DOI: 10.1515/ geo-2020-0057.

Kudas D., Wnęk A., Savchyn I. 2020. Prospect of development of the VRSNET reference stations network. Geomatics, Landmanagement and Landscape, 2, 51-64. DOI:10.15576/ GLL/2020.2.51

Lee D.T., Schachter B.J. 1980. Two Algorithms for Constructing a Delaunay Triangulation. Int. J. Computer Information Sci., 9, 219-242.

Mitchell A. 2005. The ESRI Guide to GIS Analysis, 2. ESRI Press.

Muzondo I.F., Combrinck L., Botai J.O., Munghemezulu C. 2015. A Spatial Analysis of Global Navigation Satellite System Stations Within the Context of the African Geodetic Reference Frame. International Association of Geodesy Symposia, Springer International Publishing. DOI:10.1007/1345_2015_199

Pokojski W., Pokojska P. 2018. Voronoi diagrams - inventor, method, applications. Polish Cartographical Review, 50(3), 141-150. DOI:10.2478/pcr-2018-0009 
Prawirodirdjo L., Bock Y. 2004. Instantaneous global plate motion model from 12 years of continuous GPS observations, J. Geophys. Res., 109, B08405. DOI:10.1029/2003JB002944.

Turen Y., Sanli D.U. 2019. Accuracy of Deformation Rates from Campaign GPS Surveys Considering Extended Observation Session and Antenna Set-Up Errors. Remote Sens., 11, 1225. DOI:10.3390/rs11101225

Uzel T., Eren K., Gulal E., Tiryakioglu I., Dindar A.A., Yilmaz H. 2013. Monitoring the tectonic plate movements in Turkey based on the national continuous GNSS network. Arab. J. Geosci., 6, 3573-3580. DOI:10.1007/s12517-012-0631-5

Wang C., Feng Y., Higgins M., Cowie B. 2010. Assessment of commercial network RTK user positioning performance over long inter-station distances. Journal of Global Positioning Systems, 9(1), 78-89. DOI:10.5081/jgps.9.1.78

Yavaşoğlu H.H., Kalkan Y., Tiryakioğlu İ., Yigit C.O., Özbey V., Alkan M.N., Bilgi S., Alkan R.M. 2018. Monitoring the deformation and strain analysis on the Ataturk Dam, Turkey, Geomatics, Natural Hazards and Risk, 9, 1, 94-107. DOI:10.1080/19475705.2017.1411400 www.asgeupos.pl [accessed: 28.08.2020]

www.kb.igs.org [accessed: 28.08.2020]

www.ngs.noaa.gov/CORS/ [accessed: 28.08.2020]

Dr inż. Dawid Kudas

Uniwersytet Rolniczy w Krakowie

Katedra Geodezji

ul. Balicka 253a, 30-148 Kraków

e-mail: dawid.kudas@urk.edu.pl

ORCID: 0000-0003-1109-114X 